\title{
GREEN MAP SYSTEMO: FERRAMENTA, CONTEÚDOS E SERVIÇOS DIGITAIS PARA PROJETOS DE CAMPI VIRTUAIS
}

\section{GREEN MAP SYSTEMO: TOOL, CONTENT AND DIGITAL SERVICES FOR VIRTUAL CAMPI PROJECTS}

\author{
Rafael Alexandre dos Reis ${ }^{1}$ \\ Maria do Carmo Duarte Freitas ${ }^{2}$ \\ Celso Yoshikazu Ishida ${ }^{3}$
}

O projeto de extensão Mapa Verde Curitiba entre tantas outras atividades, despertou a comunidade acadêmica sobre a disponibilidade das informações nos Campus da UFPR. A pesquisa objetiva desenvolver um banco de dados de conteúdos e serviços digitais para a construção de um campus virtual que seja representativo da Universidade Federal do Paraná - UFPR. A metodologia se fundamentou na revisão de outros projetos de campi virtuais ao redor do mundo e, na busca por conteúdos informacionais digitais. A outra fase consta de pesquisa de campo com visita aos espaços da universidade e análise de registro fotográfico e desenho em mapas, seguida de pesquisa em sítios institucionais sobre a atividade exercida pela unidade visitada. A base servirá para municiar a outra proposta que visa facilitar o acesso a informação e localização dos espaços para a comunidade acadêmica. Os resultados apoiarão projetos que criem o Campus Virtual da UFPR.

Palavras chave: campus virtual; mapas; banco de dados.

The objective of the research is to develop a content and digital service database to building a virtual campus that represents Federal University of Paraná - UFPR. The methodology relied on the review of another virtual campi projects around the world and, in searching for digital information contents. The

\footnotetext{
${ }^{1}$ Graduado em Engenharia da Produção (UFPR) e Mestrando do Programa de Pós-Graduação em Engenharia da Produção (UFPR).

${ }_{2}^{2}$ Professora da Universidade Federal do Paraná. Engenheira Civil (Universidade de Fortaleza), Mestre e Doutora em Engenharia da Produção pela Universidade Federal de Santa Catarina. mcf@ufpr.br

${ }^{3}$ Professor da Universidade Federal do Paraná. Bacharelado em Informática, Mestrado em Informática e Doutorado em Métodos Numéricos em Engenharia, pela UFPR, e Doutorado Sandwich em Matemática Aplicada - Université Paris-Sud XI. celsoishida@ufpr.br
} 
other phase is about field research visiting university spaces and analyzing of photographs and maps drawings, followed by researches in institutional sites about the activity performed by the visited university. The base will serve to equip the other proposal facilitating the information access and the localization of the spaces to the academic community. The results will support projects that are supposed to create the Virtual Campus of UFPR.

Keywords: virtual campus; maps; digital information.

\section{Introdução}

Constata-se que há cerca de 20 anos um uso intenso de tecnologia da informação na universidade com o intuito de aumentar seu alcance educacional, especialmente devido aos recentes avanços em educação virtual, ensino a distância, ensino distribuído, aprendizagem eletrônica (e-learning) e aprendizagem em rede (Web-based learning).

Para Jafari \& Sheehan (2003), instituições têm percebido o potencial da Internet como porta de entrada a gama de informações que as universidades possuem. Isso fez com que, em alguns casos, seus websites se tornassem coleções desordenadas de menus e links acerca do campus, o que tornou o site um ambiente difícil de usar e muito pouco amigável para o usuário. Como uma solução para isso, as universidades disponibilizam motores de busca em suas páginas para ajudar os usuários a encontrar as informações desejadas. Rapidamente, porém, segundo Jafari \& Sheehan, o motor de busca, mesmo com recursos de pesquisa avançada, tornou-se inútil. As webpages simplesmente oferecem muita informação, porém de maneira desordenada, de acordo com estes autores.

Trazendo esse panorama à realidade da UFPR, evidencia-se a má organização das informações acerca da universidade na plataforma web. Especificamente, a localização exata das diversas unidades da instituição, bem como a atividade por elas exercida, o contato do pessoal responsável e links que redirecionem o usuário às suas homepages são dados e conteúdos que não se encontram levantados e tampouco organizados de forma a serem facilmente acessíveis pelos usuários.

Em face dessa realidade surge o projeto campus virtual da UFPR, que pretende por meio da construção de um mapa representativo interativo e 
virtual, trazer o universo da informação disponível de forma organizada e de fácil manuseio pelo usuário. Faz-se necessário então o levantamento de dados sobre a estrutura física e acadêmica da universidade para ser utilizado num posterior mapeamento, bem como a busca por conteúdos informacionais digitais disponibilizados por projetos de campi virtuais já implantados.

O presente artigo será apresentado como se segue: a seção 2 apresenta alguns conceitos fundamentais cujos assuntos estão diretamente relacionados com o objetivo deste artigo, a seção 3 mostra a metodologia utilizada para o alcance do objetivo, já a seção 4 traz os resultados obtidos e a seção 5 conclui este artigo.

\section{Conceitos fundamentais}

A aplicação do e-learning nas organizações têm sido, nos últimos anos, uma atitude capaz de trazer muitas vantagens competitivas às organizações. E-learning (i.e., electronic learning) foi definida pela ASTD como "um amplo conjunto de aplicações e processos, como a aprendizagem em rede, aprendizagem virtual (computer-based learning), salas de aula virtuais e colaboração digital. Ele inclui a entrega de conteúdo via Internet, intranet / extranet (LAN / WAN), áudio e vídeo, transmissão via satélite, TV interativa e CD-ROM". (KAPLAN-LEISERSON, 2002).

O conceito de e-learning direcionado a criação de um portal enquanto campus virtual de uma universidade, de acordo com Ast \& Gerfen (2003), ajuda a instituição a:

-criar uma comunicação mais abrangente e mais consistente no campus;

-melhorar a experiência total do campus e a qualidade dos resultados acadêmicos;

-fortalecer as relações entre os alunos, permitindo que os alunos permaneçam mais ligados à universidade;

-atingir grupos da comunidade com conteúdos específicos;

-contribuir para o crescimento e desenvolvimento pessoal de cada aluno; -aumentar a eficácia dos serviços de apoio ao estudante;

-permitir a integração total de dados sobre os cursos on-line e serviços do campus. 
Ainda segundo Ast \& Gerfen (2003), um Campus Virtual complementa a presença física de uma instituição, fornecendo muitos dos aspectos interativos e comunitários que os alunos e professores experimentam em um campus tradicional. O produto criado no espaço virtual oferece às instituições um lugar único em que alunos, professores e servidores técnico-administrativos visitem várias vezes por dia e dependerem dela como sua fonte primária de informação. Este também serve como um recurso para futuros alunos e exalunos venha a ter acesso e visitar o campus real com freqüência, mas ainda assim ver o campus virtual como uma ferramenta valiosa para ter acesso a informações acerca do campus.

Eisler (2000) define Campus Virtual como um ponto único e integrado para um acesso abrangente a informações, pessoas e processos. Embora os portais tenham um conjunto de funcionalidades e características em rápida evolução, eles podem ser descritos como interfaces de usuário personalizadas e customizadas que oferecem aos usuários acesso a informações internas e externas ao Campus. As oportunidades criadas no Campus Virtual são:

-um portal de entrada a informações;

-pontos de acesso para grupos constituintes;

-mecanismos de comunicação; e

-centros comunitários e de aprendizagem. (EISLER, 2000)

Eisler (2003) complementa que os projetos de implementação de um portal virtual do campus devem envolver a comunidade acadêmica de forma colaborativa no desenvolvimento de respostas a três perguntas simples:

-A quem se destina o campus virtual, ou seja, quem será o usuário?

-O quê o portal fornecerá aos usuários?

-Por que você está fazendo um portal virtual para seu campus?

Para Graves \& Hale (2003), na era da informação, a organização, apresentação e manutenção dos dados são tarefas cada vez mais complexa. Anunciada como o remédio para a sobrecarga de informação e sistemas de incompatibilidades, os portais são um tema quente para organizações acadêmicas. Portais de informação são vistos como a solução para a redundância de dados e a maneira de integrar aos sistemas em um conjunto harmonioso e capaz de fornecer aos usuários uma fonte de informação para 
todas as necessidades. Embora esta visão de um portal corporativo seja excelente, é muitas vezes confrontada com uma realidade muito diferente.

Para ilustrar esta pesquisa, buscaram-se as universidades que contemplam projetos de campi virtuais já finalizados e implantados com sucesso que serão listados nos itens a seguir.

\subsection{Universidade de São Paulo - USP Virtual}

A Universidade de São Paulo desenvolveu um projeto de campus virtual que já se encontra online e acessível pelo site www.uspvirtual.com.br. Por meio de um mapa virtual desenvolvido em Flash, o usuário pode navegar entre as unidades universitárias de forma prática e simples. Ao clicar em qualquer unidade universitária disposta no mapa, o visitante é então redirecionado a outra página, com mapa específico para essa unidade e opções de navegação, entre Seção de Alunos, Biblioteca, Salas de Aula e outros ambientes. Nesta página também existem fotos e informações detalhadas sobre a localização da unidade, bem como uma lista detalhada de cursos e outros serviços oferecidos por ela.

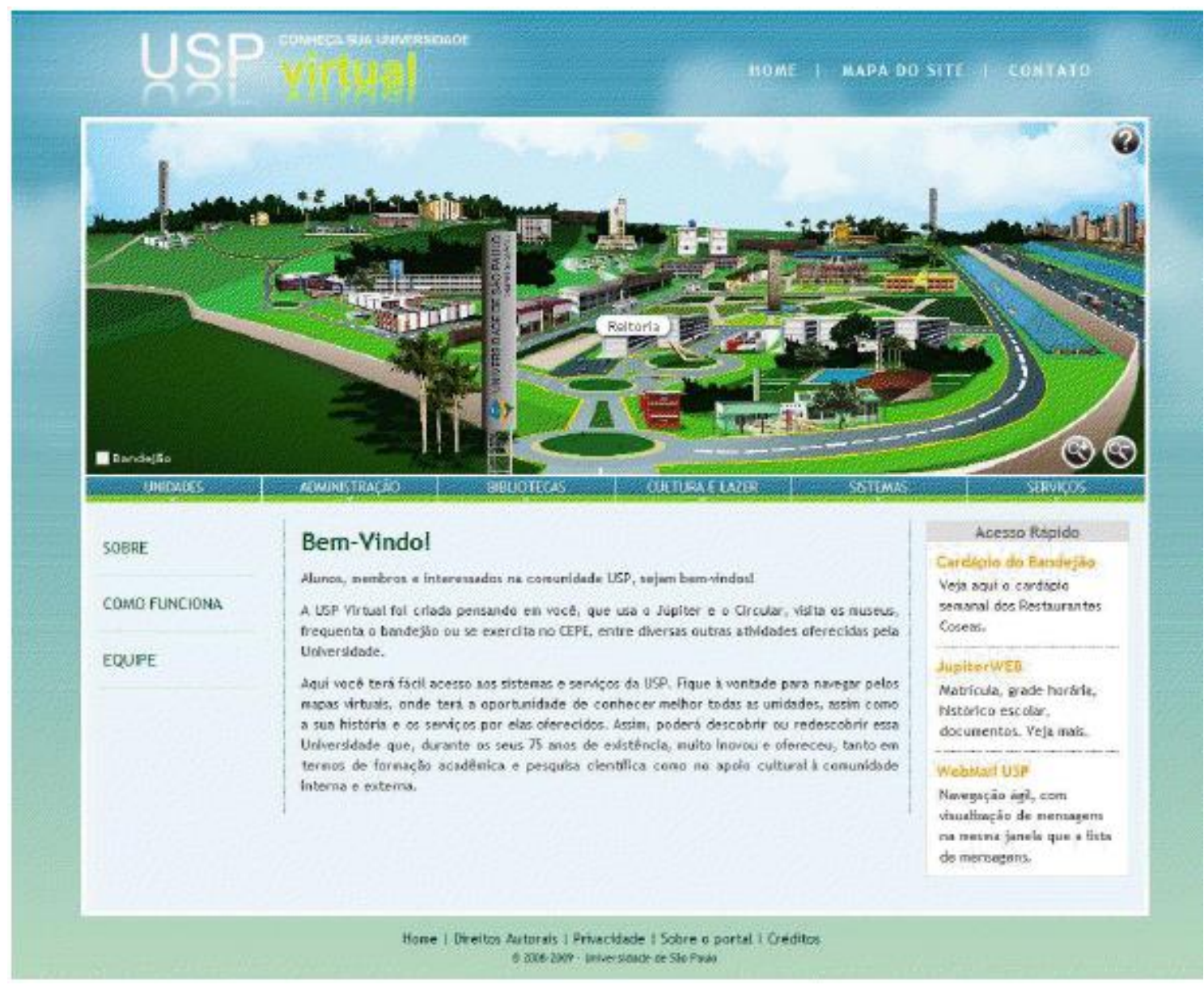


Figura 1. Tela inicial da USP virtual

Para usuários que não consigam visualizar ou não desejem usar o mapa desenvolvido em flash, existe um menu de navegação disposto também na página principal, com links que redirecionam o visitante para a página de todas as unidades do complexo universitário, da mesma forma do mapa.

\subsection{Universidade do Sul de Santa Catarina - UniSul Virtual}

O portal desenvolvido pela Universidade do Sul de Santa Catarina, Unisul Virtual, não possui aplicativos em flash ou mapas ilustrativos. Por meio do menu situado à esquerda (Figura 2), o usuário pode ter acesso as informações acerca da instituição. Por meio dos links disponíveis no site, podese ter acesso aos cursos ofertados, seus objetivos e conteúdos. Além disso, o portal disponibiliza a interação do corpo acadêmico da universidade por meio de um blog. Vídeos mostrando seminários, formaturas e outras informações sobre a instituição também se encontram disponíveis ao usuário no seu campus virtual. O portal não possui informações apenas direcionadas a alunos e professores da universidade, mas a qualquer pessoa que esteja interessada em ingressar ou apenas conhecer a instituição. 

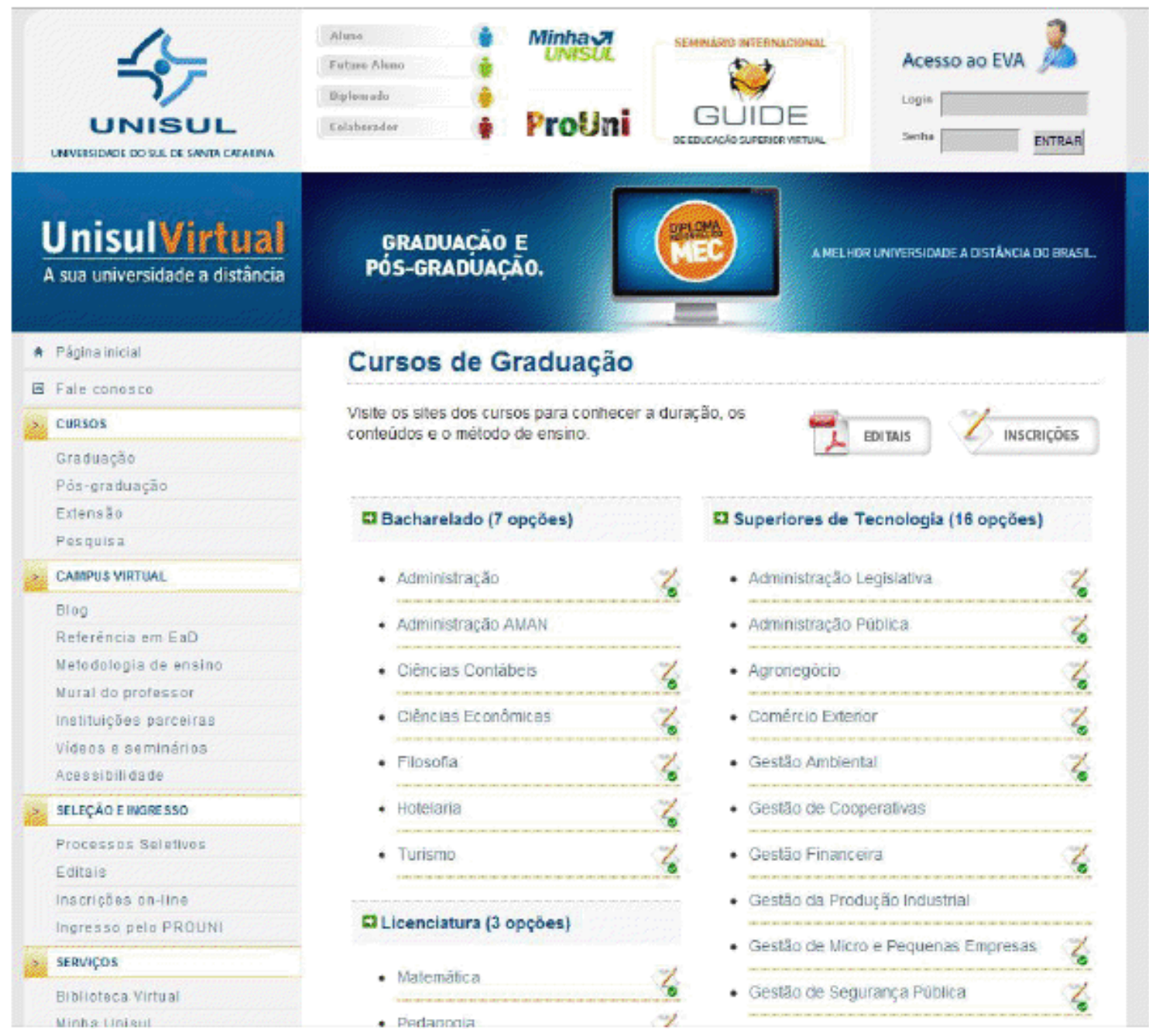

\section{Cursos de Graduação}

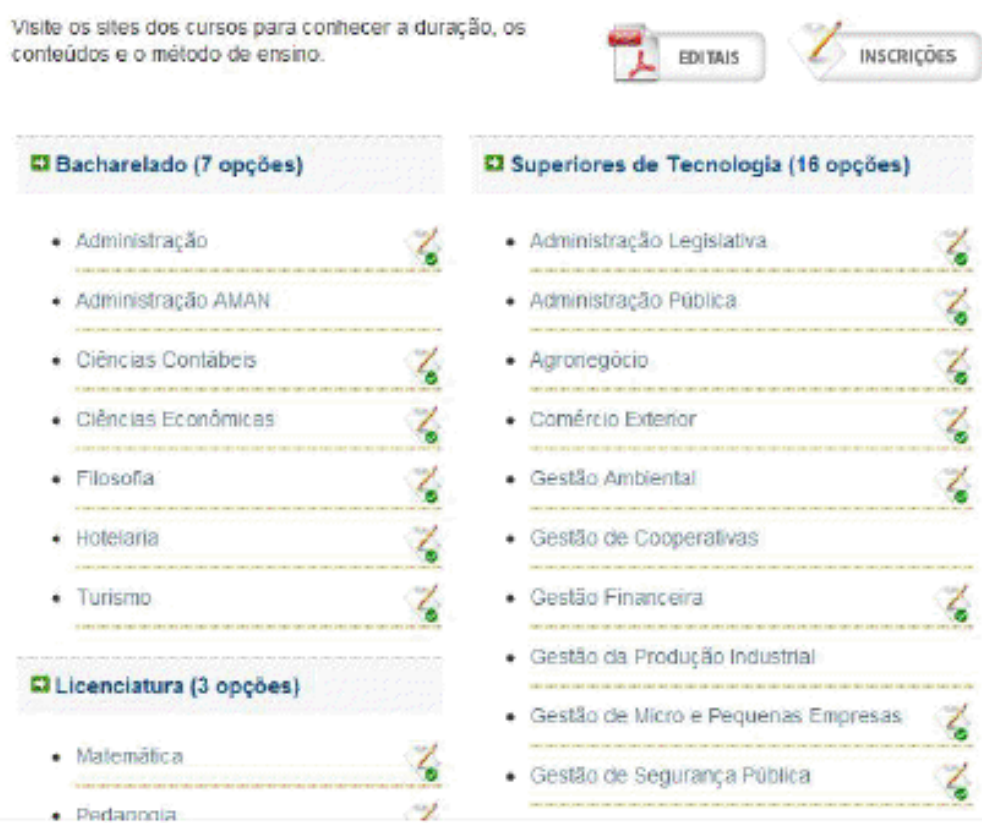

Figura 2. Unisul Virtual

\subsection{Universidade de Brasília - UnB}

A Universidade de Brasília possui um campus virtual desenvolvido em flash e com animações em 3D. Segundo definição própria, o campus virtual da UnB "é um espaço que visa mostrar com clareza as construções e os espaços destinados à cultura, lazer e serviços. Ao lado direito do mapa, há textos sobre cada um dos prédios e uma breve descrição de sua função e história. Ao navegar pelo tour virtual, é possível se sentir dentro de um ônibus que circula entre todos os prédios. Caso a procura seja pela localização de faculdades e institutos que não têm sede própria, essa não é a melhor forma de busca. $O$ Portal UnB criou uma seção em Serviços chamada Localize-se no campus. Lá o internauta poderá encontrar o local de funcionamento de todos os 
departamentos além de lanchonetes, restaurantes, bancos e livrarias." (TOUR PELA UNB, 2010)

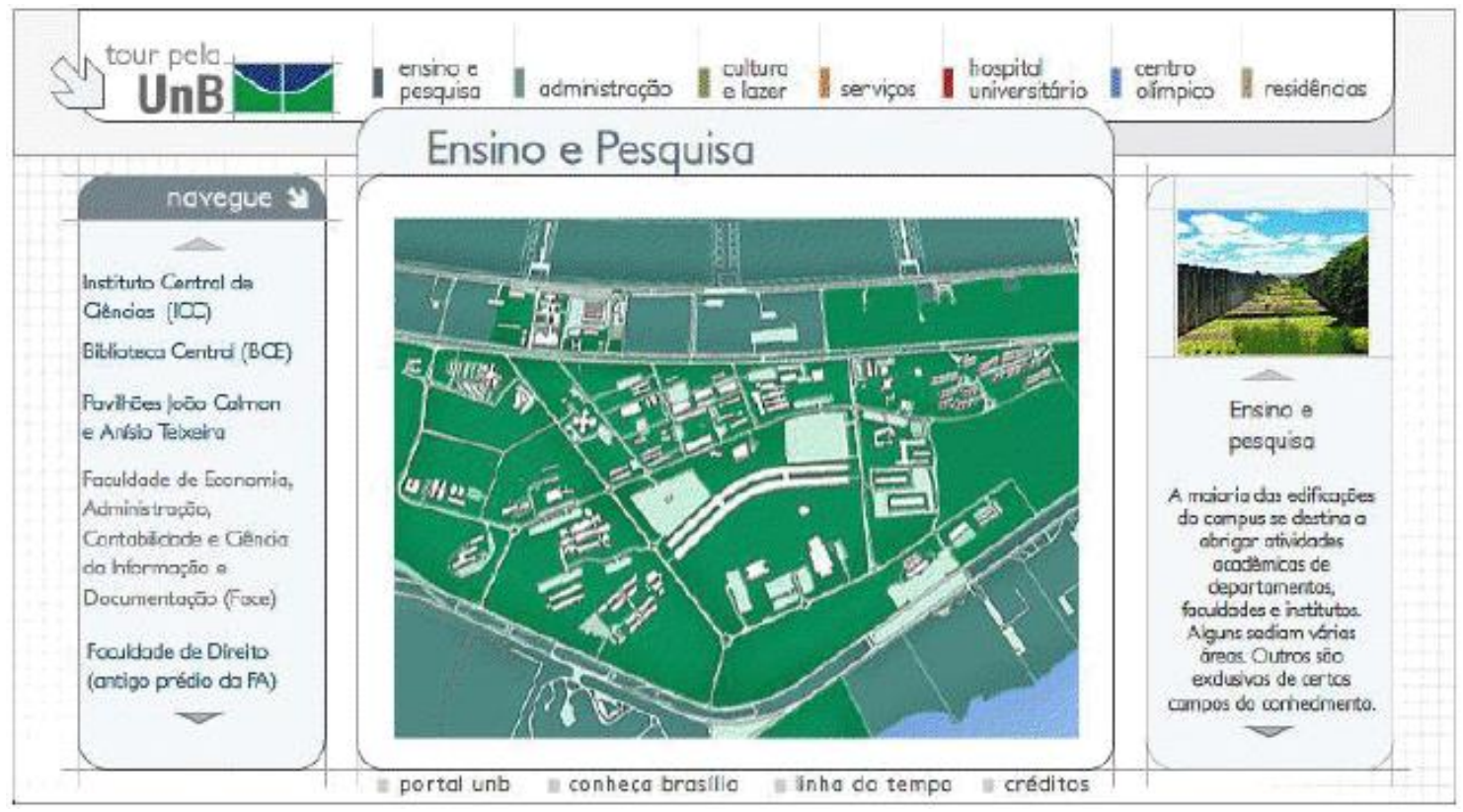

Figura 3. Tour pela UnB

Neste caso, observa-se que na figura 3, o usuário interage com o mapa por meio dos menus acima e à esquerda. Ao clicar em uma das opções acima, o menu à esquerda mostra as unidades correspondentes à opção requerida. $O$ mapa, por sua vez, aproxima a imagem virtual em 3D ao setor correspondente. Após isso, ao acessar um dos links do menu à esquerda, o mapa destaca a unidade clicada ou, em um maior nível de detalhe, aproxima a imagem até se obter o nível de um observador no solo, para assim mostrar uma foto real do local.

\subsection{Faculdade de Economia e Gestão da Universidade Nova de Lisboa}

Para conhecer a universidade de Lisboa, os usuários têm acesso a um mapa virtual localizado no portal da instituição. Os pontos anexados ao mapa fazem referência às unidades que compõem a universidade. Navegando pelos pontos, o visitante terá acesso a informações detalhadas acerca do local, seu histórico e fotos. 

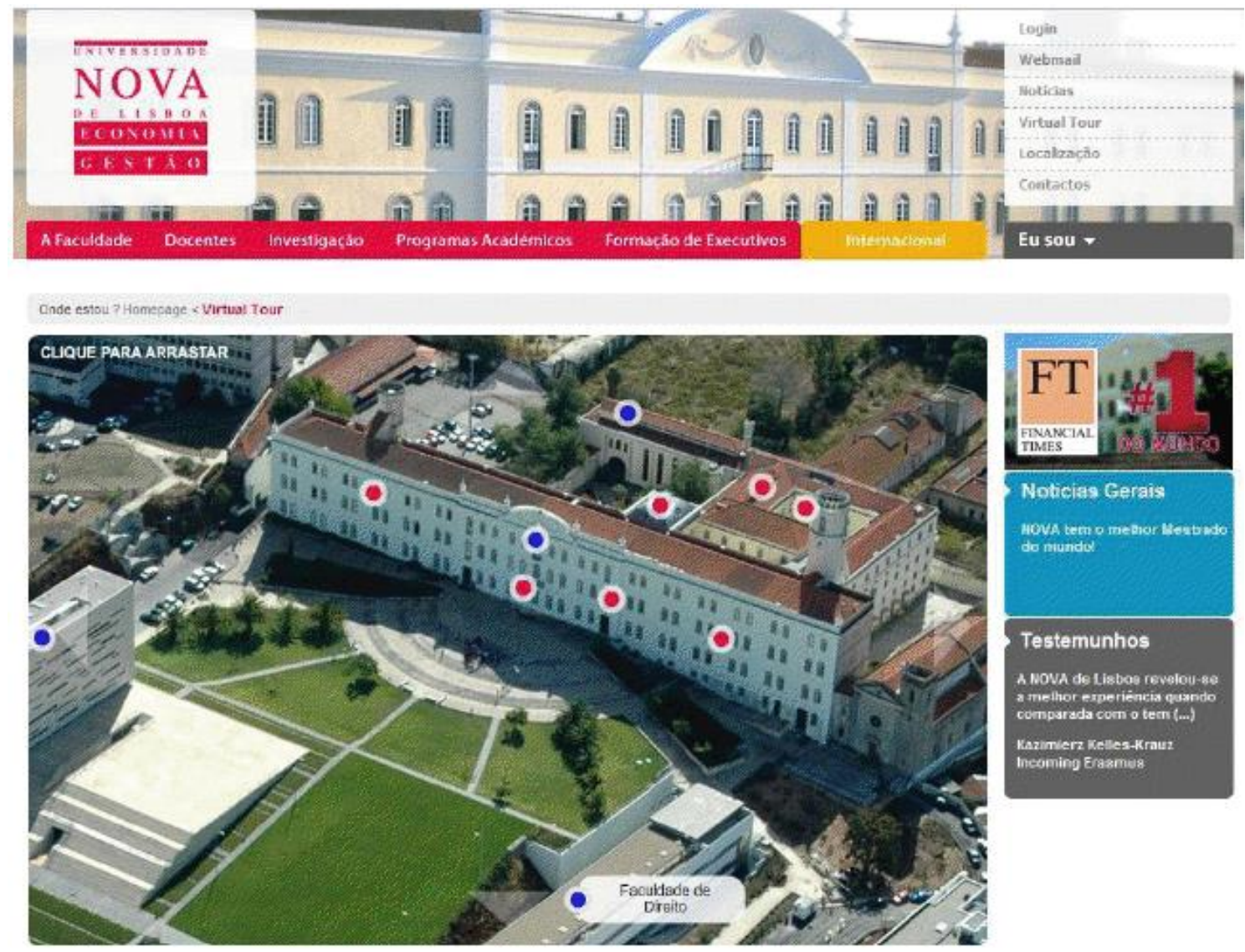

Testemunhos

A MOVA de Lisbas revelou-se a methor emperiencias quando Kanimierz Kellea-kraus: heoming Erasmus

Figura 4. Universidade Nova de Lisboa

\subsection{University of Stirling}

O campus virtual da universidade de Stirling, na Inglaterra, é composto por uma foto panorâmica do campus e, anexados à foto, os nomes das principais unidades da instituição. O usuário ao clicar em um dos nomes, será redirecionado a um vídeo explicativo da unidade. Este vídeo contém informações sobre que trabalhos são desenvolvidos em tal unidade, seu histórico e depoimentos de alunos e professores sobre o local. As figuras 5 e 6 a seguir ilustram o campus virtual da Universidade de Stirling. 


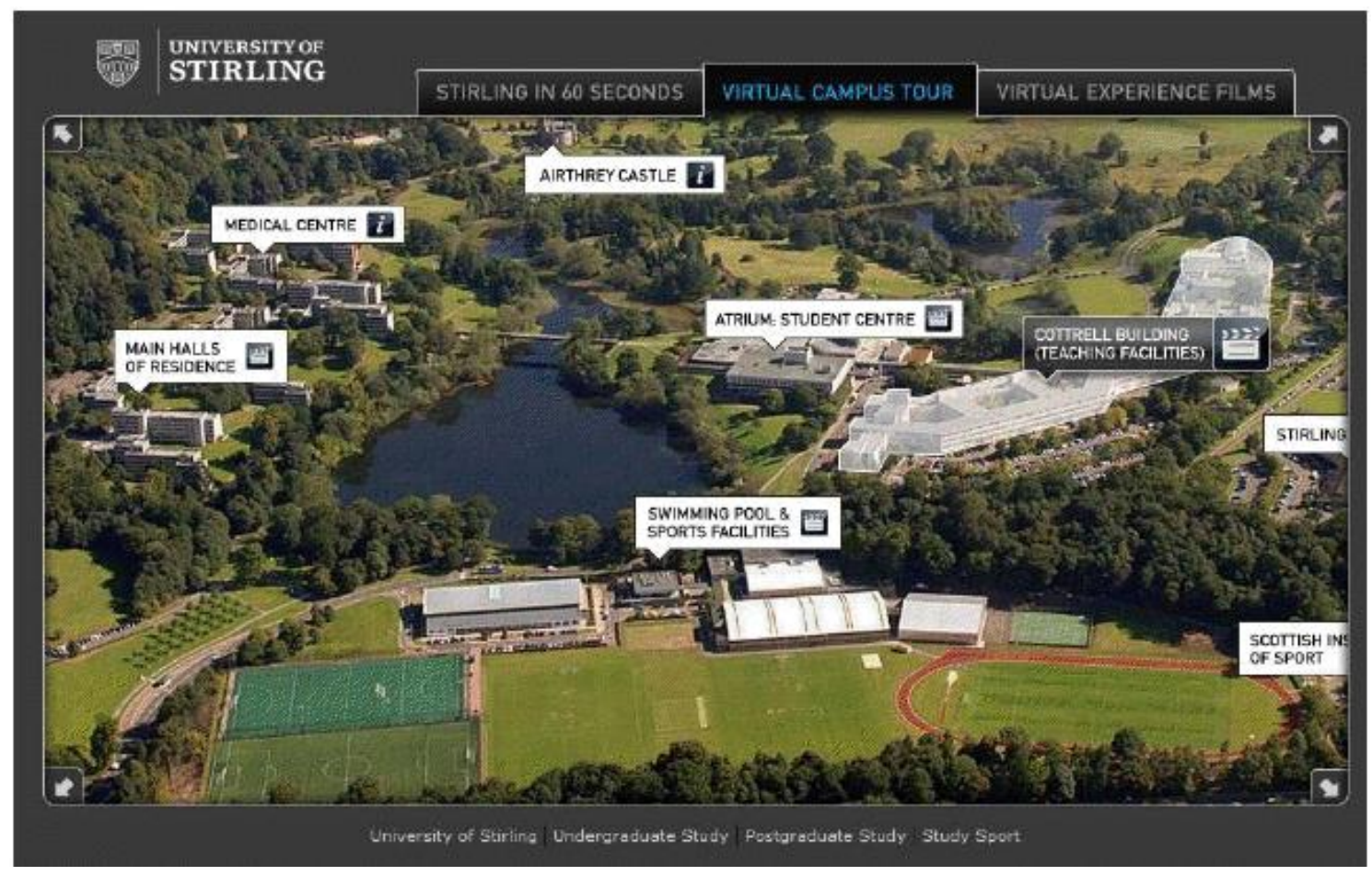

Figura 5. Campus Virtual da University of Stirling

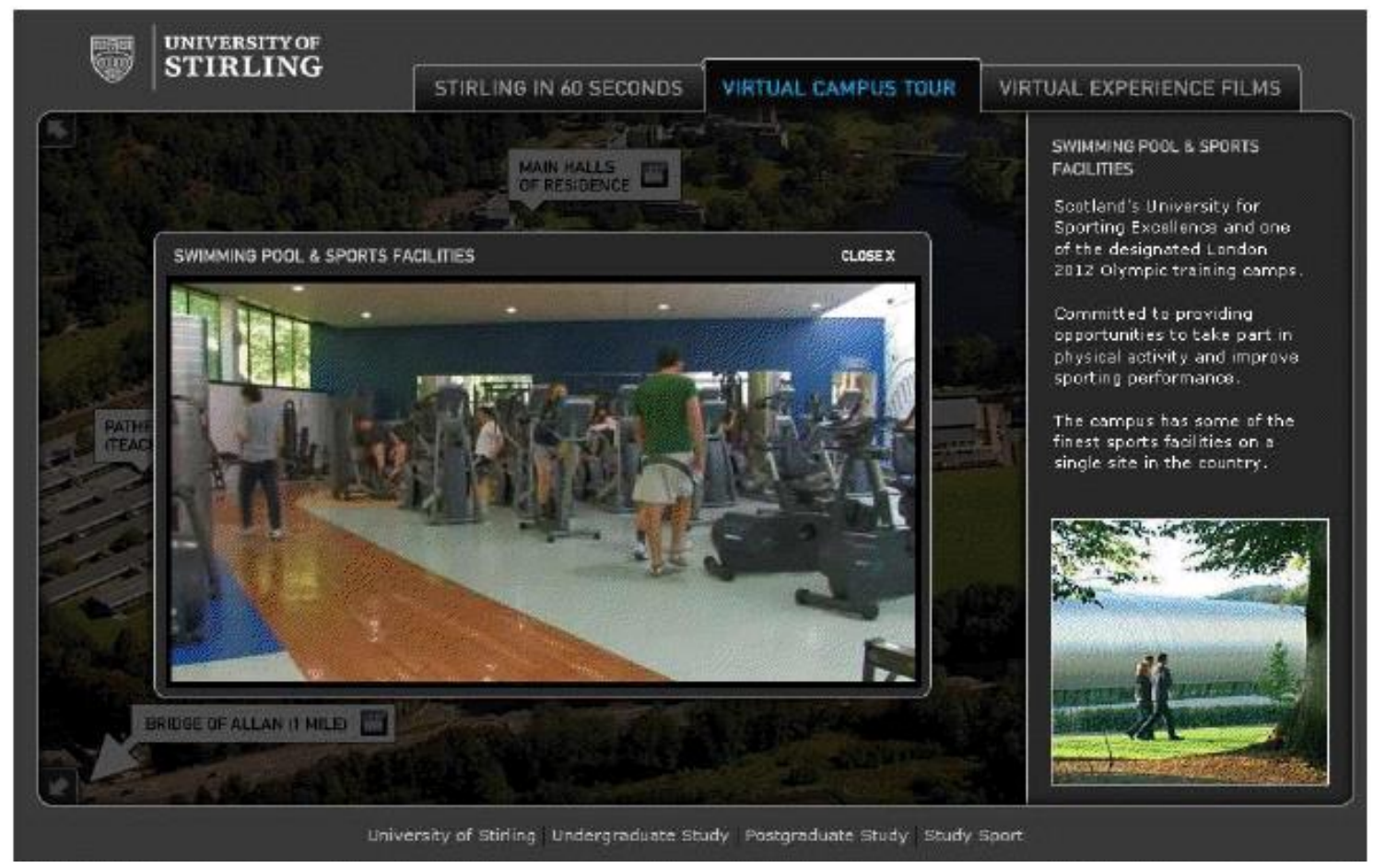

Figura 6. Campus Virtual da University of Stirling

Os projetos de campus virtual das universidades investigada conduziram esta pesquisa. A seguir o método escolhido para o desenvolvimento da base com os conteúdos para implantação do campus virtual da UFPR, objetivo final desta investigação. 


\section{Apresentação e Metodologia do Mapa Verde Curitiba}

O primeiro contato com Wendy Brawer, idealizadora por Green Map, ocorreu em maio de 2009 e a ideia era inserir Curitiba nesse projeto, um sistema online que congrega o mapeamento das zonas verdes do mundo inteiro.

O mapeamento das áreas relacionadas à sustentabilidade ambiental se dá por meio de uma linguagem iconográfica universal. Estes ícones somente podem ser agregados ao mapa da cidade pela equipe de mapmakers responsável. No caso de Curitiba, o Grupo de Pesquisa em Ciência, Informação e Tecnologia já inseriu um total de 123 ícones na cidade de Curitiba, oriundos de informações coletadas da comunidade por meio de oficinas (workshops).

Ao longo dos três anos de projeto, diversificadas oficinas já foram realizadas, tendo como público-alvo tanto alunos de graduação e pósgraduação, também crianças estudantes de escolas públicas e sociedade em geral.

O mapa verde, portanto, possui dois canais principais de intervenção na sociedade: o primeiro consiste das oficinas, nas quais os participantes são encorajados a perceber como podem desenvolver ações em prol do meio ambiente próximas ao local onde vivem e contribuir com a inserção de ícones no mapa virtual. A segunda consiste na disponibilização do mapa virtual de forma aberta na internet, no qual a sociedade pode consultá-lo e interagir de forma a tornar a cidade de Curitiba um ambiente mais ambientalmente sustentável (figura 7). 


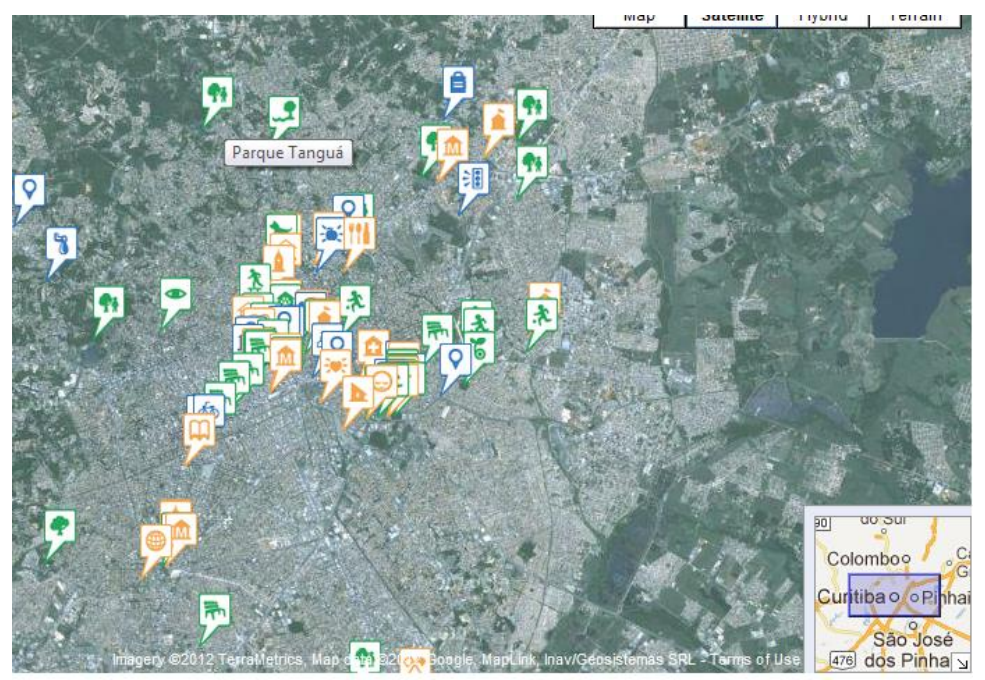

FIGURA 7 - O MAPA VERDE DE CURITIBA

Durante os três anos de projeto, foram atingidos diretamente por meio dos workshops e exposições do mapa verde cerca de 600 pessoas. Com a interação de usuários do mapa e os impactos causados pelo mapa online na mídia paranaense. Estima-se que mais de três mil pessoas já conheça e perceba algum impacto da metodologia do mapa verde em seus cotidianos. $O$ quadro abaixo mostra uma síntese das ações realizadas (quadro 1).

\begin{tabular}{|l|c|c|}
\hline Evento & Participantes diretos & Forma de abordagem \\
\hline Conferência Internacional de Educação para o Desenvolvimento Sustentável & 80 & Oficina \\
\hline Alunos de Arquitetura e Urbanismo I & 30 & Oficina \\
\hline Alunos de Arquitetura e Urbanismo II & 20 & Oficina \\
\hline Alunos de Doutorado da UTFPR & 40 & Oficina \\
\hline Evento Sugestao & 150 & Stand de divulgação \\
\hline Evento Sugestao II & 150 & Stand de divulgação \\
\hline Colégio Estadual Amancio Moro & 35 & Oficina \\
\hline Encontro Latino-americano de Edificaçôes e Comunidades Sustentáveis & 40 & Oficina \\
\hline Encontro de Extensão e Cultura da UFPR & 20 & Oficina \\
\hline Escola Estadual Santos Dumont & 25 & Oficina \\
\hline
\end{tabular}

QUADRO 1 - AÇÕES REALIZADAS PELO PROJETO

O impacto do projeto na mídia paranaense também foi expressivo. Reportagens na TV UFPR e na TV Paulo Freire foram realizadas, além de uma 
reportagem na Gazeta do Povo. O mapa verde possibilita também um impacto no poder público na medida em que atua como denunciante de práticas ou situações prejudiciais ao meio ambiente. Houve um caso de poluição de rio em Curitiba que foi denunciado por um participante de oficina morador da região, inserido no mapa da cidade e explorado pela mídia como matéria jornalística.

Diante dos resultados é que surge a ideia de propor o Mapa para UFPR com base na busca de conteúdos que atendam a necessidade da comunidade academica.

\section{Metodologia}

Observando os tipos de pesquisas científicas estabelecidas por Santos (2002), o presente trabalho relata uma pesquisa de campo, com caráter exploratório e cujos procedimentos de coletas de dados fundamentaram-se na pesquisa documental e na pesquisa-ação, concomitantemente.

Para Thiollent (1986), "pesquisa-ação é um tipo de pesquisa social com base empírica que é concebida e realizada em estreita associação com uma ação ou com a resolução de um problema coletivo e no qual os pesquisadores e os participantes representativos da situação ou problema estão envolvidos de modo cooperativo ou participativo."

A pesquisa documental define-se por ser a procura por informações que já estejam registradas em alguma unidade e que são passíveis de consulta livre. (ASSOCIAÇÃO BRASILEIRA DE NORMAS TÉCNICAS, 2000).

O trabalho, portanto, dividiu-se em dois momentos: A pesquisa documental acerca dos campi da UFPR e a construção de um banco de dados de conteúdos informacionais e serviços.

A pesquisa documental seguia duas frentes de trabalho: a busca por informações sobre unidades da UFPR em sítios online que fossem oficiais da instituição e, de forma complementar, a visitação presencial do pesquisador nos campi. O pesquisador e seus colaboradores então, por meio de anotações, desenhos em pranchetas e captação de imagens fotográficas, buscavam representar as unidades da UFPR em alto nível de detalhe em suas visitas. A coleta abrangeu departamentos, setores, laboratórios, empresas Junior, bibliotecas, centros de estudo e aperfeiçoamento, diretórios, pró-reitorias, núcleos, entre outras unidades. 
Em um segundo momento, o banco de dados acerca da universidade ia sendo alimentado na medida em que as informações eram trazidas ao laboratório de pesquisa e passavam por um processo de triagem, que buscava confirmar a veracidade de cada informação. O banco de dados foi construído em uma planilha online compartilhada entre o pesquisador e seus colaboradores, onde todos os envolvidos na pesquisa podiam editá-la e visualizá-la. Ao mesmo tempo em que essa planilha ia sendo desenvolvida, um mapa iconográfico representativo da UFPR, usando a plataforma do GreenMap System@ era formado para que a informação sobre a localização exata de cada unidade fosse preservada. A plataforma Green Map System@ $@$ foi escolhida por meio de um estudo realizado simultaneamente a este, nesta mesma instituição, por Oliveira (2010) e intitulado "Desenvolvimento de um Sistema Informacional que simule a estrutura física de uma cidade universitária".

\section{Resultados}

A presente pesquisa obteve dois resultados principais, como anteriormente citados. $O$ banco de dados em forma de planilha, na figura 7 , está composto por 192 unidades ligadas à Universidade Federal do Paraná.

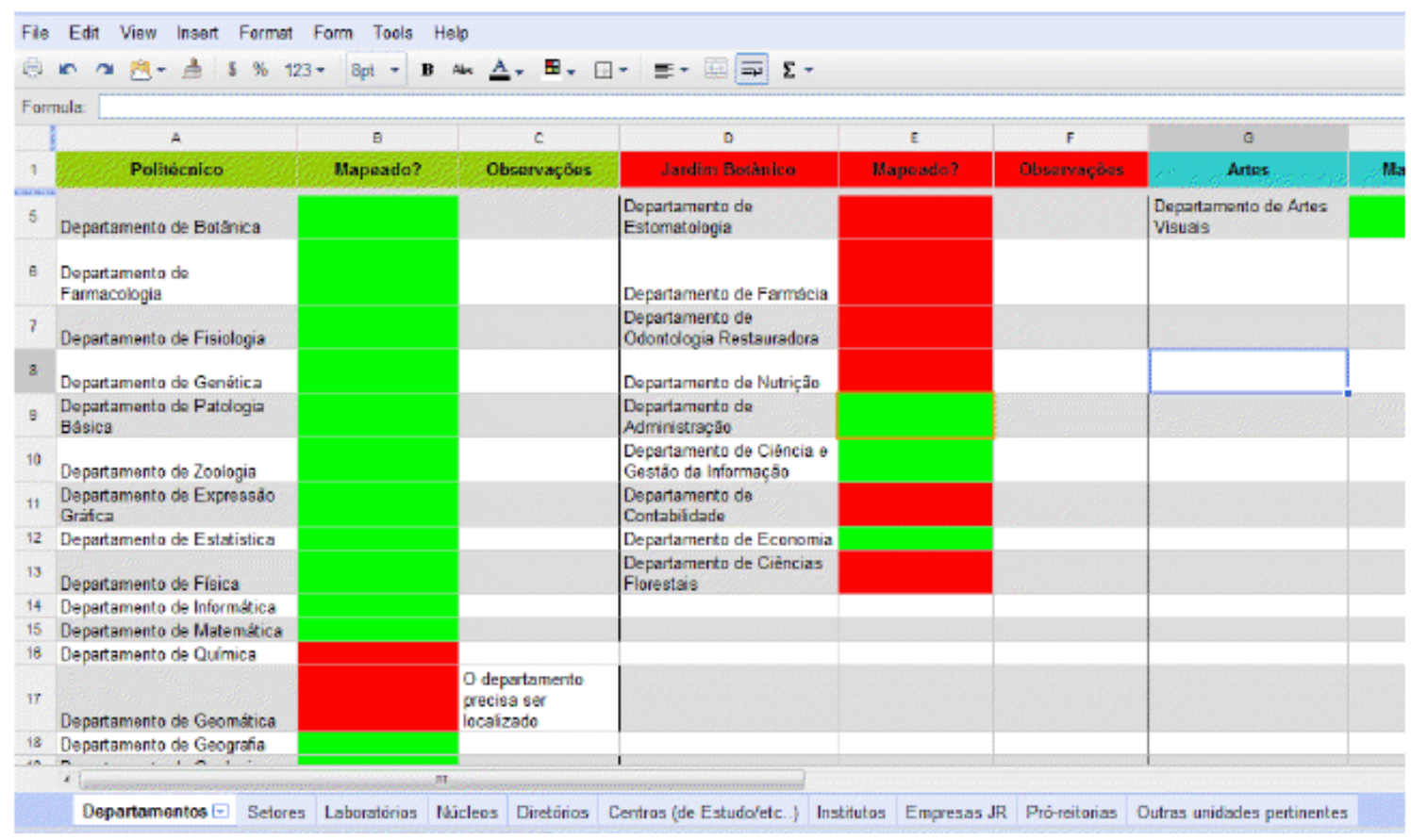

Figura 7. Banco de Dados. 
Foi elaborada uma planilha para cada divisão de unidades da instituição (departamentos, setores, laboratórios, etc.), e cada planilha está subdividida em porções físicas da universidade como são convencionalmente conhecidas. A coluna "Mapeado?" diz respeito a transposição das informações ao mapa iconográfico, sendo usada a cor verde se a informação foi devidamente transpassada, ou vermelho no caso contrário.

$\mathrm{Na}$ forma como foi citado anteriormente, esses dados eram transpassados a um mapa iconográfico na plataforma GreenMap System@, juntamente com demais informações acerca do serviço prestado pelo local, telefones e email para contato, homepage, material multimídia, endereço, e outras informações individuais. O mapa conta com 183 ícones espalhados pelos campi da UFPR.

A seguir, ilustração do mapa iconográfico:

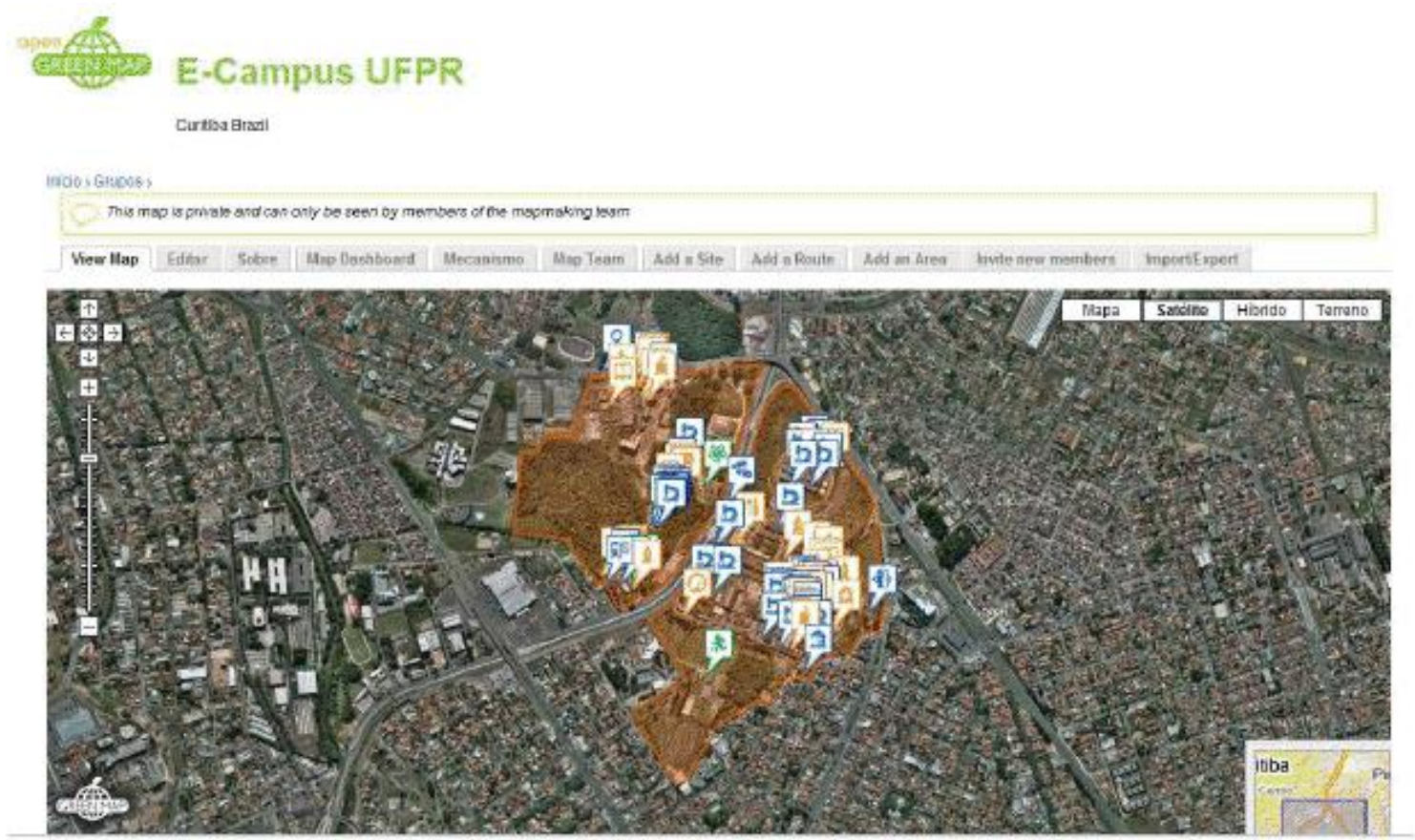

Figura 8. Visão Geral do campus Centro Politécnico no mapa iconográfico

Ao clicar em um dos ícones referentes às unidades, um balão se expande e traz ao usuário as informações acerca do local, com informações pesquisadas, fotografias do local e vídeos em certos casos, conforme ilustrado na Figura 10. 


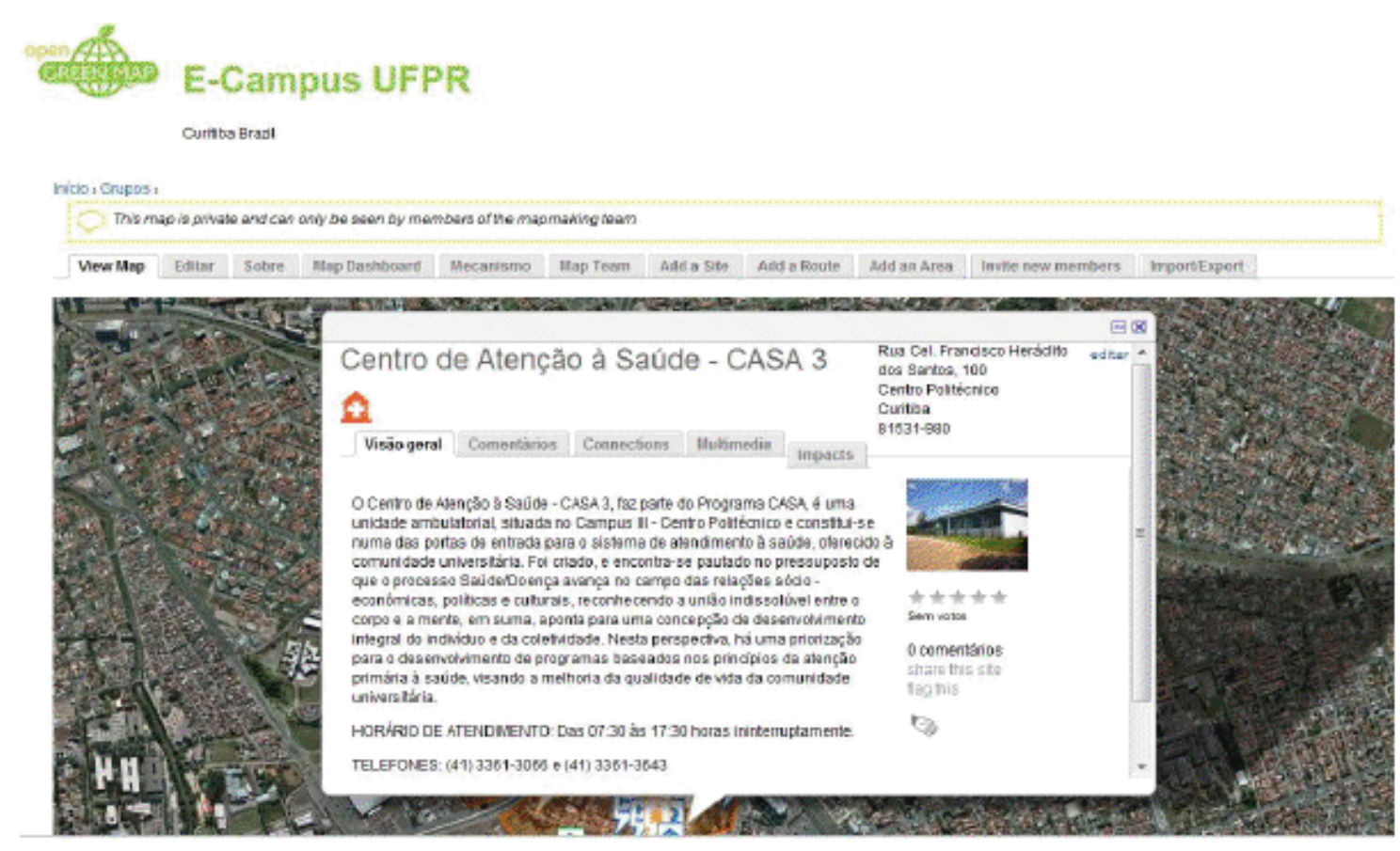

Figura 9. Visão do mapa iconográfico

O conteúdo informacional pesquisado e armazenado no banco de dados encontra-se disposto no mapa temático. Este permite aos usuários acesso aos dados de funcionamento e atendimento das unidades da UFPR. Acrescente-se que o projeto poderá ser continuado com a participação da comunidade universitária e inserção de pontos tidos como sustentáveis. Os ícones selecionados tratam de apresentar os pontos relacionados ao modo de vida sustentável e cultura e sociedade.

\section{Conclusão}

Durante o tempo em que o projeto Mapa Verde Curitiba está ativo foram diversos resultados tanto no campo acadêmico como na intervenção com a comunidade em geral. Já são 12 (doze) trabalhos acadêmicos apresentados em Congressos e demais eventos científicos. Duas monografias uma de especialização e outra de graduação. Entre eles cita-se duas premiações em dois eventos:

- O IV Encontro Latino-americano de Edificações e Comunidades Sustentáveis - ELESC, realizado em Vitória/ES entregou o premio de $2^{\circ}$ colocado na categoria pôsteres para o trabalho de apresentação do Mapa Verde. 
- O 18ํㅡㄹ Evento de Iniciação Científica - EVINCI - premiou como 1ㅇ lugar o trabalho de apresentação da linguagem iconográfica do mapa verde como metodologia para o desenvolvimento sustentável.

A pesquisa para a proposta deste artigo com a ferramenta solucionou o problema inicial, na medida em que levantou os dados acerca da UFPR e os distribuiu de maneira organizada em um banco de dados. Têm-se como perspectiva a divulgação desses dados à comunidade acadêmica ou a quem tiver interesse, por meio do campus virtual da UFPR. Julga-se que tal fato não aconteceu principalmente pela razão de que, até então, não havia um banco de dados como o que foi desenvolvido nesta pesquisa. O campus virtual da UFPR tem, portanto, o que é necessário para ser desenvolvido e se tornar referência nacional no que tange a portais acadêmicos.

O projeto lançado por meio da plataforma do GreenMap Systems ${ }^{\circledR}$ prestará um serviço digital a toda à comunidade universitária.

O retorno das atividades anteriores por parte da sociedade é o que motiva ainda mais a continuar este inspirador trabalho.

\section{Em destaque:}

Em contato a equipe de Curitiba com a idealizadora global do projeto de Mapas Verdes recebeu de Wendy Brawer uma resposta gratificante:

"Your letter is wonderful, Rafael, Danilo, Marciano and Carminha - you have a remarkable breadth of work! Exciting and inspiriting.

I will be passing this to one of the university students here and see if she can make us an info graphic about it, if this is OK with you. Keep up the wonderful work!

Thank you so much - this made my day!!

Wendy Brawer" 


\section{REFERÊNCIAS}

AST \& GERFEN. Building a Virtual Campus. Publicado em Designing Campus Portals, Capítulo XIV, p. 238-255. Hershey: Information Science Publishing, 2003.

EISLER, D.L. Campus Portal Strategies. Publicado em Designing Campus Portals, Capítulo VI, p. 68-88. Hershey: Information Science Publishing, 2003.

FACULDADE de Economia e Gestão da Universidade Nova de Lisboa: virtual tour. Disponível em http://www.fe.unl.pt/index.php?page=528. Acessado em Agosto de 2010.

GRAVES \& HALE. Portals: Your Institution's Reputation Depends on Them. Publicado em Designing Campus Portals, Capítulo IV, p. 37-50. Hershey: Information Science Publishing, 2003.

JAFARI \& SHEEHAN. Designing Campus Portals. Hershey: Information Science Publishing, 2003.

KAPLAN-LEISERSON, E. ASTD Learning Circuits Glossary. Disponível em: http://www.learningcircuits.org/glossary.html. Acessado em Julho de 2010.

PORTAL UnB. Disponível em http://www.unb.br/unb/tour/index.php. Acessado em Agosto de 2010.

SANTOS, A. R. Metodologia científica: a construção do conhecimento. 5.ed. São Paulo: DP\&A, 2002.

THIOLLENT, M. Metodologia da pesquisa-ação. 2. ed. São Paulo: Cortez, 1986.

UNISUL VIRTUAL. Disponível em http://www.unisul.br/unisulvirtual/home.html. Acessado em Agosto de 2010.

UNIVERSITY OF STIRLING: VIRTUAL CAMPUS TOUR. Disponível em http://www.external.stir.ac.uk/tour/flash.php. Acessado em Agosto de 2010. 
USP VIRTUAL. Disponível em http://www.uspvirtual.usp.br/. Acessado em Agosto de 2010. 